Article

\title{
Experimental Research on the Impactive Dynamic Effect of Gas-Pulverized Coal of Coal and Gas Outburst
}

\author{
Haitao Sun ${ }^{1,2}$, Jie Cao 1,2,*(1), Minghui Li ${ }^{3, *}$, Xusheng Zhao ${ }^{1,2}$, Linchao Dai ${ }^{1,2}$, \\ Dongling Sun ${ }^{1,2}$, Bo Wang ${ }^{1,2}$ and Boning Zhai ${ }^{1,2}$ \\ 1 State Key Laboratory of the Gas Disaster Detecting Preventing and Emergency Controlling, \\ Chongqing 400037, China; dreamsht@163.com (H.S.); cq_zxs@163.com (X.Z.); dailinchao@126.com (L.D); \\ cqsdl@126.com (D.S.); wangbo@ymail.com (B.W.); rik_1211@hotmail.com (B.Z.) \\ 2 Gas Research Branch, China Coal Technology Engineering Group Chongqing Research Institute, \\ Chongqing 400037, China \\ 3 State Key Laboratory of Coal Mine Disaster Dynamics and Control, Chongqing University, \\ Chongqing 400030, China \\ * Correspondence: cqcaoj@126.com (J.C.); mhli@cqu.edu.cn (M.L.); Tel.: +86-159-0238-8870 (M.L.)
}

Received: 12 February 2018; Accepted: 27 March 2018; Published: 30 March 2018

\begin{abstract}
Coal and gas outburst is one of the major serious natural disasters during underground coal, and the shock air flow produced by outburst has a huge threat on the mine safety. In order to study the two-phase flow of a mixture of pulverized coal and gas of a mixture of pulverized coal and gas migration properties and its shock effect during the process of coal and gas outburst, the coal samples of the outburst coal seam in Yuyang Coal Mine, Chongqing, China were selected as the experimental subjects. By using the self-developed coal and gas outburst simulation test device, we simulated the law of two-phase flow of a mixture of pulverized coal and gas in the roadway network where outburst happened. The results showed that the air in the roadway around the outburst port is disturbed by the shock wave, where the pressure and temperature are abruptly changed. For the initial gas pressure of $0.35 \mathrm{MPa}$, the air pressure in different locations of the roadway fluctuated and eventually remain stable, and the overpressure of the outburst shock wave was about $20 \sim 35 \mathrm{kPa}$. The overpressure in the main roadway and the distance from the outburst port showed a decreasing trend. The highest value of temperature in the roadway increased by $0.25^{\circ} \mathrm{C}$ and the highest value of gas concentration reached $38.12 \%$ during the experiment. With the action of shock air flow, the pulverized coal transportation in the roadway could be roughly divided into three stages, which are the accelerated movement stage, decelerated movement stage and the particle settling stage respectively. Total of $180.7 \mathrm{~kg}$ pulverized coal of outburst in this experiment were erupted, and most of them were accumulated in the main roadway. Through the analysis of the law of outburst shock wave propagation, a shock wave propagation model considering gas desorption efficiency was established. The relationships of shock wave overpressure and outburst intensity, gas desorption rate, initial gas pressure, cross section and distance of the roadway were obtained, which can provide a reference for the protection of coal and gas outburst and control of catastrophic ventilation.
\end{abstract}

Keywords: coal and gas outburst; laboratory simulation experiment; two-phase flow of a mixture of pulverized coal and gas; shock wave; propagation model

\section{Introduction}

Coal and gas outburst accident is one of the most serious hazards to the safe production of underground coal mines. In recent years, the forecasting and prevention technology of coal and 
gas outburst have been continuously developed, coal and gas outburst accident in China showed a downward trend, as shown in Figure 1 [1-3]. Due to the poor understanding of the mechanism of outburst dynamic disasters, the proportion of outburst accident counts and death toll to the total accident counts and death toll is relatively high, reaching up to an average of $35.4 \%$ and $32.4 \%$ in the year 2010 2016. In the event of a coal and gas outburst accident, the high-pressure gas and the generated broken coal (rock) in the coal seam can move from at least tens of meters to several hundred meters in the roadway, resulting in the damage of the underground facilities, causing the gas explosion and further associated disasters. For example, on 21 November 2009, Xinxing Coal Mine in Heilongjiang Province at 1:37 p.m. in the No. 15 coal seam, a coal (rock) and gas outburst occurred [4]. Afterwards, the gas countercurrent was raised to the second level, causing a gas explosion at 2:19 a.m., 108 deaths were counted. Therefore, it is urgently necessary to carry out an in-depth research on the migration rules of two-phase flow of a mixture of pulverized coal and gas during the coal and gas outburst process, which can provide guidance for the safety precautions arrangement of outburst, and efficiently prevent the occurrence of associated secondary disasters.

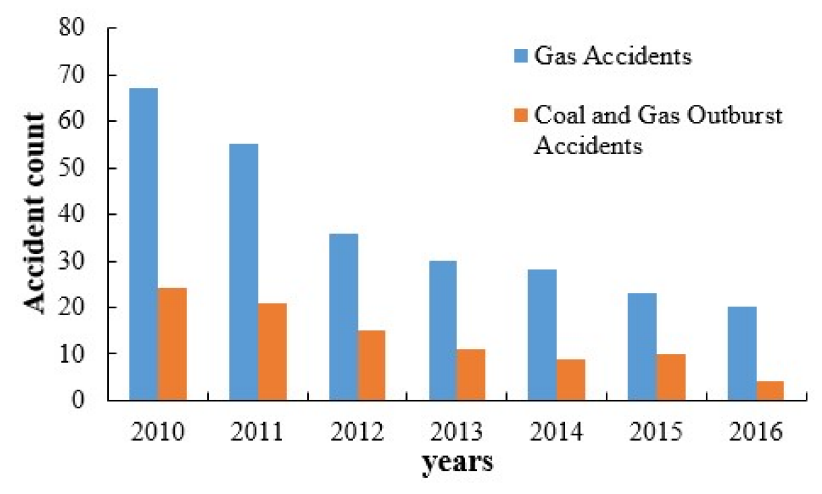

Figure 1. 2010-2016 gas accident statistics of coal mine in China.

Since the first outburst accident recorded in 1834, many theoretical hypotheses of coal and gas outburst have been established through on-site investigations, theoretical analysis, numerical simulation and laboratory simulation. At present, the understanding of outburst mechanism has been unified into the "comprehensive action hypothesis". The coal and gas outburst process contains stages of preparation, initiation, development and termination. The overall process is the integrated result of the concurrence of stress, gas and the physical and mechanical properties of coal-rock mass [5]. Previous researches were generally carried out based on field statistic data. Satostudied the geological features near the site based on the field statistic data of the third largest gas outburst at Sunagawa Coal Mine in Japan in 1986. The result showed that the faulting of the normal fault might be the direct cause and the predominant mechanism of the gas outburst [6]. Fisne et al. comprehensively analyzed the possible causes of outburst accidents based on the outburst occurrence in the specific mining and geological conditions in Turkey in the period from 1969 to 2012, [7]. Zhai et al. analyzed 153 coal and gas outburst accidents in Pingdingshan, China, and obtained the main factors that affect the outburst were the geological structure, depth of burial depth, coal seam thickness, roof and floor lithology and mining operation mode [8]. Due to its huge devastating, artificially induced coal and gas outburst in the coal mine site is not feasible. Scholars began to carry out similar simulations of coal and gas outburst in the laboratory with numerical analysis software or test equipments. The similar simulations can help to reveal the energy conversion mechanism of coal and gas outburst during multi-field coupling conditions, the experiments also intend to ascertain the criteria for outburst occurrence. $\mathrm{Xu}$ et al. used RFPA numerical simulation software to simulate the process of coal and gas outburst [9]. Xu et al. partitioned the process of coal and gas outburst into two stages: initiation and development, then they ran a simulation study on the initiation stage of the outburst utilizing by software FLAC3D and COMET3 [10]. Alexeev developed a true triaxial test device, which can simulate 
the underground stress of 10,000 m below the surface. The device was applied to study the influence of moisture content on the outburst, and the results showed that when the water absorption rate is higher than 3\%, the outburst-type fracture formation is impossible [11]. Sobczyk et al. constructed a self-development two-dimensional load test equipment, then carried out a series of experiments to study the relationship between the uniaxial compressive strength, gas pressure and the outburst risk [12-14]. Peng et al. used outburst test equipment to analyze the influence of permeability and non-uniform loading, gas pressure and moisture content [15-17]. In the recent two years, scholars such as Tu [18], Zhao [19] and Xu [20] studied the effects of gas enrichment and adsorption on the outburst by simulation tests. Therefore, to a certain extent, they promoted the understanding of coal and gas outburst mechanism.

At present, the research on the outburst mechanism mainly focuses on analysis of its occurrence conditions, but few researches focus on the development process of coal and gas outburst, such as the lack of studies on the rule of coal and gas flow and the shock wave disaster effect in the roadway. By investigating the development process of coal and gas outburst, Otuonye et al. set up a two-dimensional mathematical model for the flow of gases and the propagation of the induced shock waves. By adopting numerical solutions, the results were obtained that air velocity generated by the shock wave is slower than the shock wave propagation velocity, and the shock wave intensity will decay drastically when crossing the fork roadway [21]. Fedorov et al. analyzed the mixture flow behavior in the development process of coal and gas outburst, and found some rules in the relationship of depression waves, shock waves, initial concentration and diameter of particles in coal-and-gas mixtures. By considering desorption of fixed gas at the surface of coal particles, they demonstrated that the increase in the content of solid particles and fixed gas in the coal and gas mixture can result the free gas pressure growth and the increasing shock wave onto the mine environment [22,23]. Sun et al. deduced the mathematical function between the parameters of pressure, density, velocity and flow in the process of outburst. They also analyzed the critical state of the two-phase flow of coal-gas and the formation mechanism of the shock wave under different flow conditions [24,25]. Based on the theories of coal spherical shell failure and the pneumatic conveying, the coal and gas flow and the transportation mechanism are analyzed by Zhao et al. [26]. Wang et al. analyzed the impact by the roadway distribution and the intensity of coal and gas outburst on the shock wave propagation from the numerical simulation, and used the self-development test device to conduct experimental verification $[27,28]$.

When studying the propagation of shock wave and the two-phase flow of a mixture of pulverized coal and gas law of coal and gas outburst, researches were mostly based on the theoretical analysis and numerical simulation. The issue is that the process of its movement is inevitably simplified, which leading to some limitations of the research results. Therefore, this paper uses the self-developed experimental device of coal and gas outburst dynamic effects to carry out the laboratory simulation experiment of two-phase flow of a mixture of pulverized coal and gas in the outburst process. The research on the rules of shock wave propagation in roadway and pulverized coal migration characteristics can help to make further improvement for the theory of coal and gas outburst prediction and provide a reference for disaster protection and catastrophic ventilation design.

\section{Experimental Equipment and Program}

\subsection{Experimental Equipment and Features}

The experiments were operated under the independent self-development coal and gas outburst dynamic simulation test device [29]. This device was designed by selecting the "fluid similar" as the dominant guideline, the systems consists of dynamic effect container, gas injection sub-system, roadway sub-system, data monitoring and acquisition sub-system and dust removal sub-system, as shown in Figure 2. This device can accomplish the physical simulation of outburst two-phase flow of a mixture of pulverized coal and gas and the pulverized coal sorting accumulation process in the 
roadway under different parameters of solid or gas. The law of the shock wave propagation along the network of the roadway can also be carried out by the device, then to provide theoretical basis for protection and control of coal and gas outburst. The specific compositions of the device are as follows:

(1) Dynamic effect container is key component of the coal and gas outburst dynamic simulation test device, and it is used to simulate the coal and gas occurrence in the outburst hole and launch the outburst. The volume is $1.88 \mathrm{~m}^{3}$ and the maximum working pressure is $5.0 \mathrm{MPa}$. There are two coal loading ports on the top of the container for filling solid experimental materials; sensor ports and gas-filled holes is on the sides; and a $300 \mathrm{~mm}$ diameter outburst port is on the front bottom. Before the test, the outburst port was sealed by two rupture disks. It was used to control the pressure difference between the two sides of the rupture disk to achieve the opening of the outburst port.

(2) Gas injection sub-system consists of controller, high-pressure cylinder group, and vacuum pump. It used to achieve accurate control of test gas pressure.

(3) Roadway sub-system is mainly used for the simulation of the mine tunnel network and consists of 4 types of 6 pipe assemblies including straight pipe assembly $(1.0 \mathrm{~m}, 1.5 \mathrm{~m})$, tee pipe assembly, right angle pipe assembly and inclined pipe assembly $\left(10^{\circ}, 20^{\circ}\right)$. Available connect by rubber mats and screws, total length up to $50 \mathrm{~m}$. The cross-sectional shape is a square with an internal size of $300 \mathrm{~mm} \times 300 \mathrm{~mm}$. A number of sensor contacts, visible windows, and cleaning windows are provided for ease of test placement, testing, and cleaning.

(4) Data monitoring and acquisition sub-system is mainly used to collect experimental data, including gas pressure, temperature, gas concentration, wind speed, etc. It has two modes: low-speed acquisition and high-speed acquisition. It can automatically switch to high-speed acquisition mode at outburst moment to ensure complete and reliable data. Its highest sampling rate is $4 \mathrm{MS} / \mathrm{s}$.

(5) The main structure of the dust removal sub-system is made of a steel plate with a thickness of $8 \mathrm{~mm}$. The overall length is $3 \mathrm{~m}$, width is $2 \mathrm{~m}$, and height is $4 \mathrm{~m}$. Dust removal is carried out by means of cloth bag filtration, to avoid polluting the surrounding environment. It was started when finish the collection and sorting of the distribution data of roadway pulverized coal after the end of the test. The main structural components include: cylinders, vent pipes, ladders, ash doors, etc. The interior of the cylinder is equipped with dust removal facilities such as filter cartridges, vibrators, and gaskets.

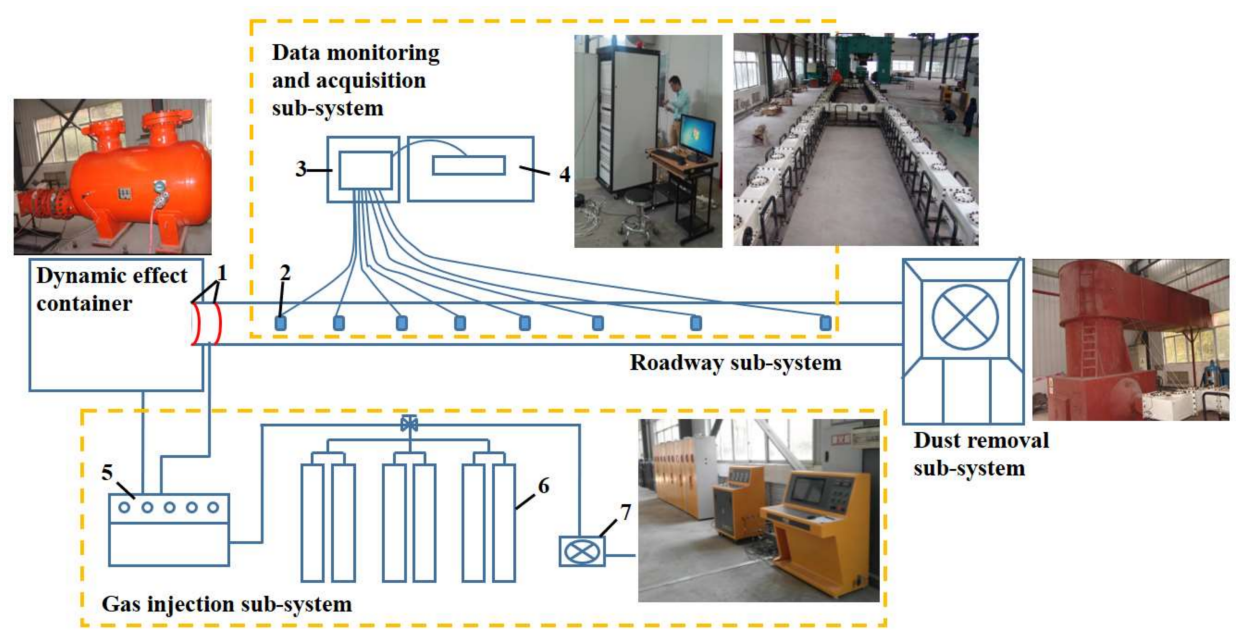

Figure 2. The simulation test device for dynamic effect of coal and gas outburst: 1 -Rupture disk; 2-Pressuretemperatureconcentration sensor; 3-Multi-function data acquisition controller; 4-Display and operating platform; 5-Controller; 6-Gas cylinder; 7-Vacuum pump. 
The features of the device include: withstanding a maximum gas pressure $5 \mathrm{MPa}$. By the pressure difference control between both sides of the rupture disk to complete the sample adsorption process and to achieve the fast initiating of the outburst port. By the replaceable components of the roadway sub-system (straight pipe $(1.0 \mathrm{~m}, 1.5 \mathrm{~m})$, tee pipe, rectangular pipe and inclined pipe $\left(10^{\circ}, 20^{\circ}\right)$ ), a various network roadway simulation of fluid routing, resistance features can be completed, the total length of the system is $50 \mathrm{~m}$. The data monitoring and acquisition sub-system with up to 90 channels and $4 \mathrm{MS} / \mathrm{s}$ velocity can collect data of gas pressure, concentration and temperature in the roadway comprehensively and at high frequency. With the collected data, the temporal and spatial evolution of parameters in the outburst dynamic disaster can be studied. Finally, the design of the dust removal sub-system can effectively avoid the ground and air pollution around the test site.

\subsection{Experimental Program}

In this research, coal samples of outburst coal seam M8 in Chongqing Yuyang Coal Mine in China were selected as experimental objects. Coal and gas outburst occurred in the coal seam for 20 times, with an average outburst intensity of $162.25 \mathrm{t}$. The $1 \mathrm{t}$ coal samples selected from $0.9 \mathrm{~mm}$ to $1 \mathrm{~cm}$ particle size pulverized coal were put into the dynamic effect container (Statistic data show that in some coal mines in Chongqing, more than $60 \%$ of the outburst coal particle size is smaller than $10 \mathrm{~mm}$. In March 1981, the outburst of coal seam No. 4 in No. 2402 roadway of Yutianbao Mine was relatively smaller in size, and the coal powder with particle size less than $10 \mathrm{~mm}$ reaches $100 \%$ ). In order to guarantee the safety of experiment, high-purity $\mathrm{CO}_{2}$ gas was used instead of methane as the experimental gas, and $0.35 \mathrm{MPa} \mathrm{CO}$ gas was injected in the dynamic effect container as the initial condition of the experiment. The roadway installation and sensors layouts can be found in Figure 3, the outburst port of the dynamic effect container is connected to the main roadway, followed by the dust removal sub-system; at $11.0 \mathrm{~m}$ of the main lane, the contact roadway is connected; The branch of roadway which is connected to the other end of the contact roadway is parallel to the main roadway. The iron plate is plugged at the both ends of the branch to simulate the blind drift or air door. After the experimental materials and the roadway are arranged, the pressure difference between both sides of the rupture disk is controlled by gas injection sub-system, so that the pressure difference is greater than the designed initiating pressure of the rupture disk. Therefore, the rupture disk is popped out rapidly by the experimental gas and then the outburst port can be opened. The initiating process is designed to simulate the actual outburst process. The rupture disk is triggered out after $1.09 \mathrm{~s}$ when the data acquisition system started to operate, and the coal and gas outburst simulation is induced.

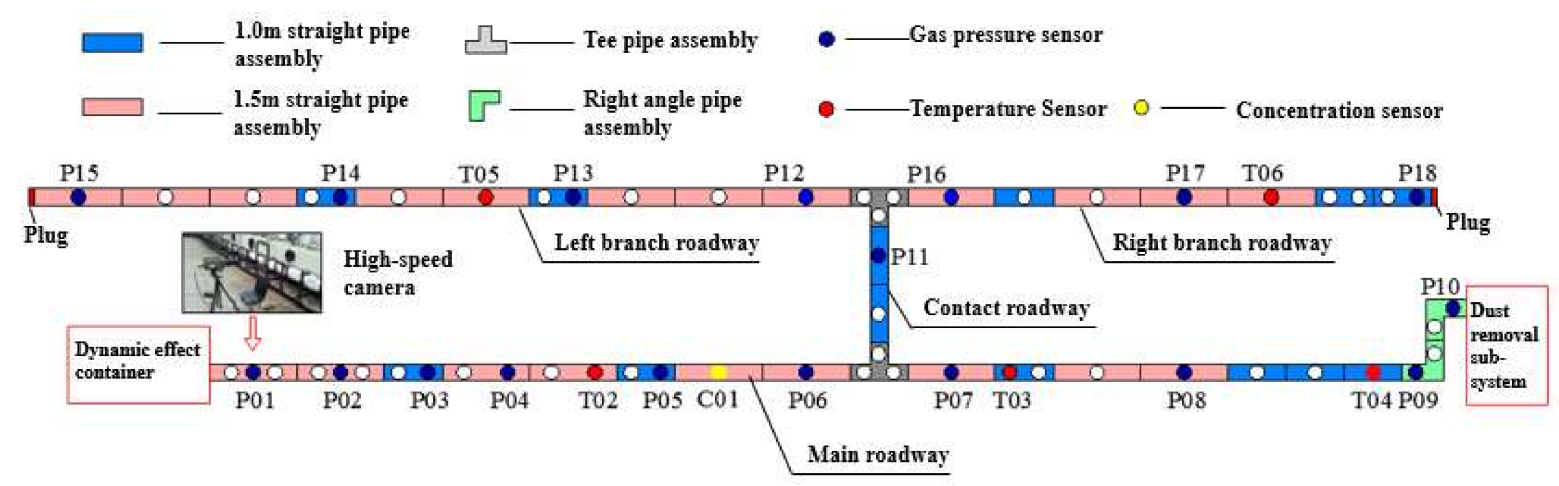

Figure 3. Schematic of test roadway and sensor layouts. 


\section{Experimental Result}

\subsection{Evolution Law of Gas Pressure in Roadway}

After the outburst occurred, the high-pressure gas carrying a large number of pulverized coal particles from the container emitted into the roadway. The air in the surrounding roadway is disturbed and forms a shock wave, making the pressure, density and temperature varied abruptly, as shown in Figure 4. It can be seen from Figure 4 that at the beginning, the sudden increase in pressure produces a large positive pressure and then rapidly decays. In very short time, the positive pressure drops to a negative pressure (initial change of P01 measuring point $<80 \mathrm{~ms}$ ), as the gas in the container protrudes continuously, the pressure gradually returns to the initial state after it circulates in several times. At the main roadway close to the outburst port (P01, P03), there are two significant changes in gas pressure before $2 \mathrm{~s}$. There are two or three small changes after $2 \mathrm{~s}$ and then gradually returns to stay stable, which may be due to the desorption of $\mathrm{CO}_{2}$ gas adsorbed in coal particles. However, at the relative far position from the outburst port (P06, P07, P09), the peak pressure gradually weakened, and the positive pressure remained constant for a long time after the gas rose. At the end of branch roadway (P15, P18), the gas pressure gradually tended to be stable after 8 to 10 fluctuations. Due to the close of the end of the branch roadway, the impact ranges of gas flow cannot continue to move forward, the shock waves were reflected and led to fluctuations increment.

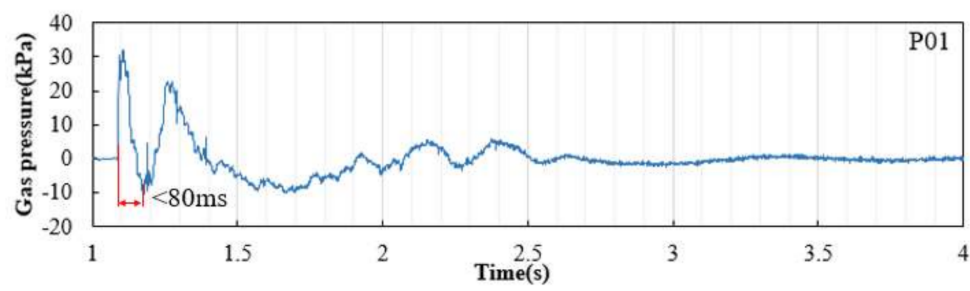

(a)

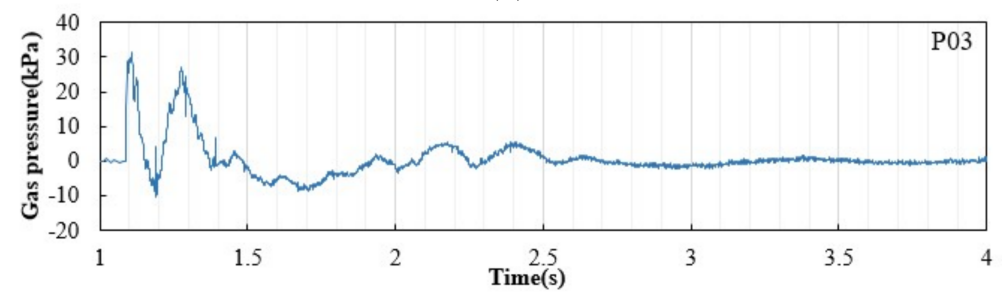

(b)

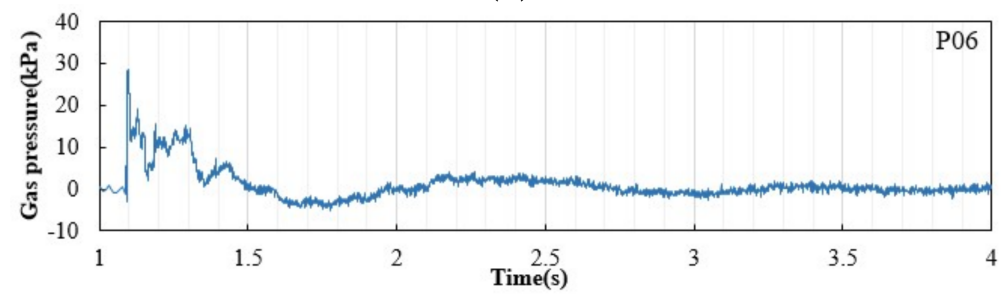

(c)

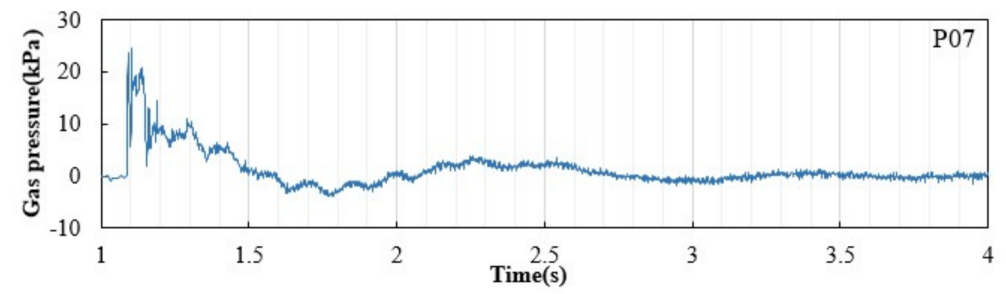

(d)

Figure 4. Cont. 


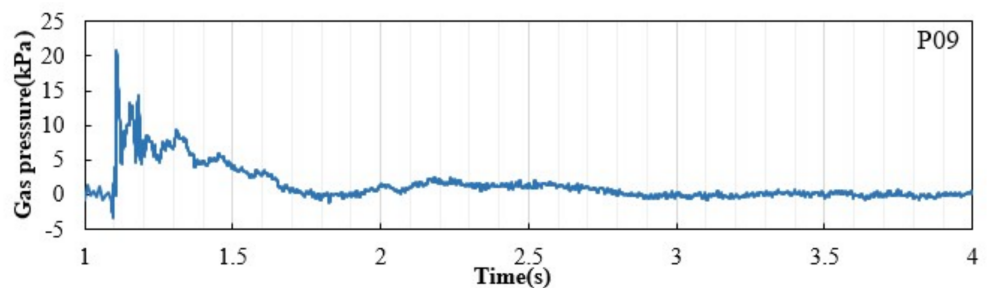

(e)

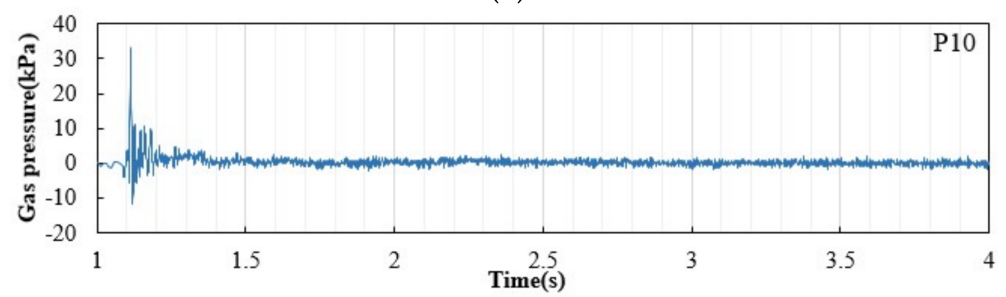

(f)

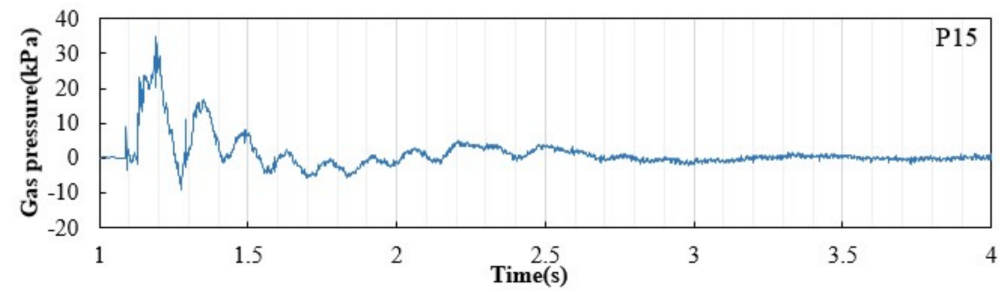

(g)

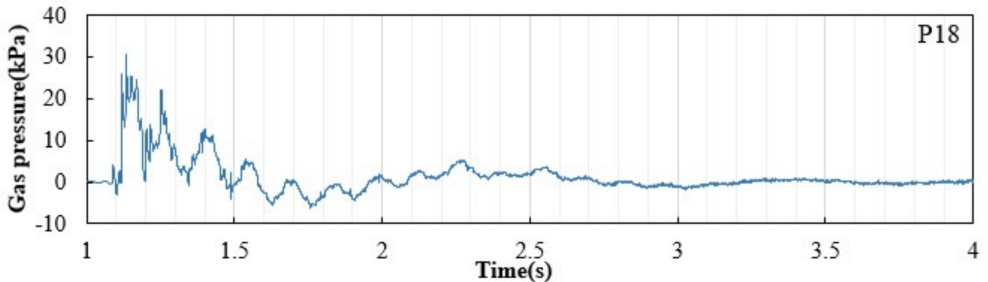

(h)

Figure 4. Evolution of gas pressure in roadway with different locations over time. (a) P01; (b) P03; (c) P06; (d) P07; (e) P09; (f) P10; (g) P15; (h) P18.

The maximum positive pressure at the initial stage equals to the overpressure on the shock wave, which is an important factor to the shock wave disasters of coal and gas outburst. The overpressure of the outburst shock wave in this experiment is about $20 \sim 35 \mathrm{kPa}$. Studies have shown that 30 50 kPa shock wave overpressure can lead to human organ damage or bone fracture, while 50 100 kPa shock wave overpressure can cause serious damage of human internal organs or even death [30]. The distribution of shock wave overpressures obtained in this experiment along the roadway are shown in Figure 5. Comparing the overpressure at different measuring points, the overpressure in the main roadway decreased with the distance from the increment of outburst port. However, in the branch roadway, the shock wave overpressures showed an increases trend due to the air flow reflection at the end of roadway. Comparing the shock wave overpressure values at the left and right branches, it could be seen at the same distance from the outburst port, the overpressure peak roughly remained the same. 


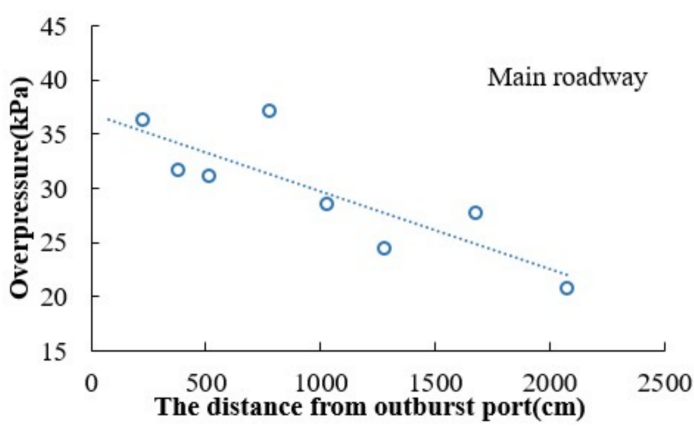

(a)

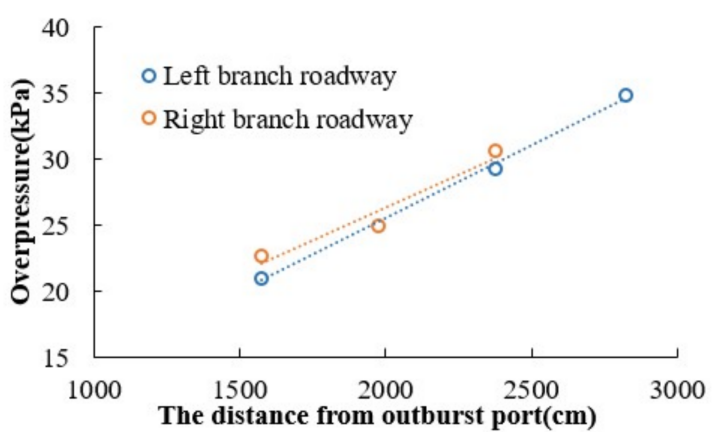

(b)

Figure 5. The distribution of shock wave overpressures along the roadway. (a) Main roadway; (b) Branch roadway.

\subsection{Evolution Law of Temperature in Roadway}

When disturbed by the shock wave of the outburst, the temperature in the roadway will rise rapidly and then become lower. Because of the severe desorption of outburst pulverized coal in the main roadway, the temperature is further reduced, which is lower than the initial temperature before its projection. The temperature relative values change curve of the main roadway and branch roadway are shown in Figure 6. It could be seen that the temperature changed relatively slowly when compared with gas pressure. The closer the main roadway to the outburst port, the faster the temperature changed. At the distance of $6.6 \mathrm{~m}$ (T02) and $20 \mathrm{~m}$ (T04) from the outburst port, the phase of relative temperature changed greater than $0{ }^{\circ} \mathrm{C}$ and it lasted for about $36.4 \mathrm{~s}$ and $86.3 \mathrm{~s}$ respectively. The temperature sensor arrangement locations in left (T05) and right (T06) branches were the same distance from the outburst port, so the temperature values change showed the same variation. The relative values change of peak temperature in main roadway was $0.25^{\circ} \mathrm{C}$, while in branch roadway was only $0.065^{\circ} \mathrm{C}$ due to the attenuation of shock wave energy.

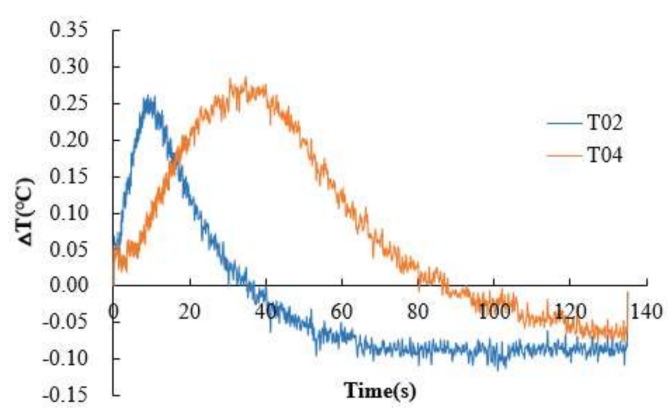

(a)

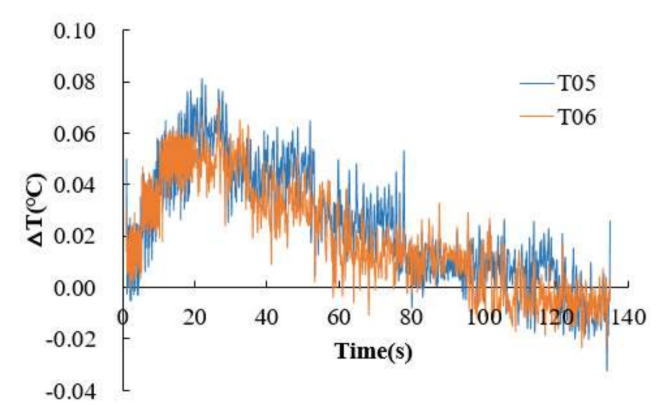

(b)

Figure 6. The temperature relative values change curve of the main roadway and branch roadway.

(a) Main roadway; (b) Branch roadway.

\subsection{Evolution law of $\mathrm{CO}_{2}$ Concentration in Roadway}

After the outburst occurred, the $\mathrm{CO}_{2}$ concentration of roadway rapidly increased, but the change of gas pressure and temperature was relatively small. In the data collection of $32 \mathrm{~s}$, the concentration reached a peak of $38.12 \%$, and then gradually decreased. Due to the lack of ventilation during the experiment, gas diffusion was slow and the concentration in the roadway was still about $4 \%$ for a certain period of time. The evolution of the concentration was consistent with the actual coal and gas outburst occurred in coal mine, as shown in Figure 7. 


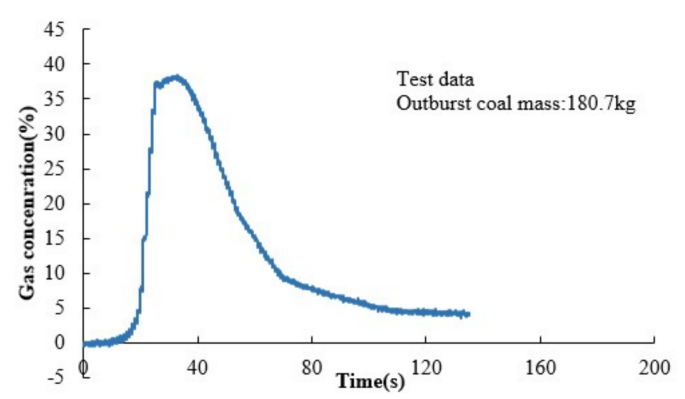

(a)

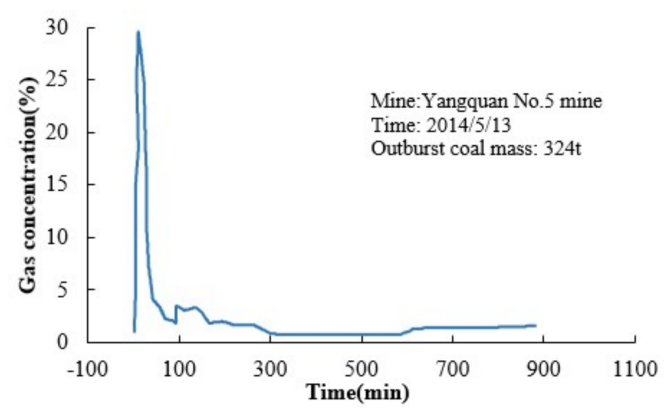

(b)

Figure 7. The $\mathrm{CO}_{2}$ concentration curve of in the main roadway. (a) Test data; (b) Field data (Zhao W. et al., 2016).

\subsection{The Migration Rule of Pulverized Coal in Roadway}

A total of $180.7 \mathrm{~kg}$ pulverized coal was gathered in this experiment, most of them were accumulated in the main roadway. With the action of shock air flow, the processes of pulverized coal transportation in the roadway could be roughly divided into three stages: the accelerated movement stage, decelerated movement stage and the particle settling stage, as shown in Figure 8. After the outburst occurred, a large number of gas discharged from the outburst hole, resulting in an instant gas accumulation and movement in roadway. The speed of its movement was far greater than the pulverized coal, and the pulverized coal was continuously accelerated in the gas flow due to the viscous force. At the same time, with the increase of speed, the resistance to the pulverized coal movement was also gradually increased. When the speed increased to a certain extent, the forward force acting on the particle swarm equilibrates with the resistance, and the accelerate stage of the pulverized coal ended. Afterwards, with the outburst development, the amount of gas overflowing out of the hole was reduced, the gas pressure was decreased, and the pulverized coal velocity was continuously decreased with the decrease of gas flow velocity. Finally, due to the outburst termination, the pressure of gas in the roadway was gradually reduced to the atmospheric pressure. When the gas velocity was slower than the pulverized coal particle suspension velocity, the coal particles began to settle down.

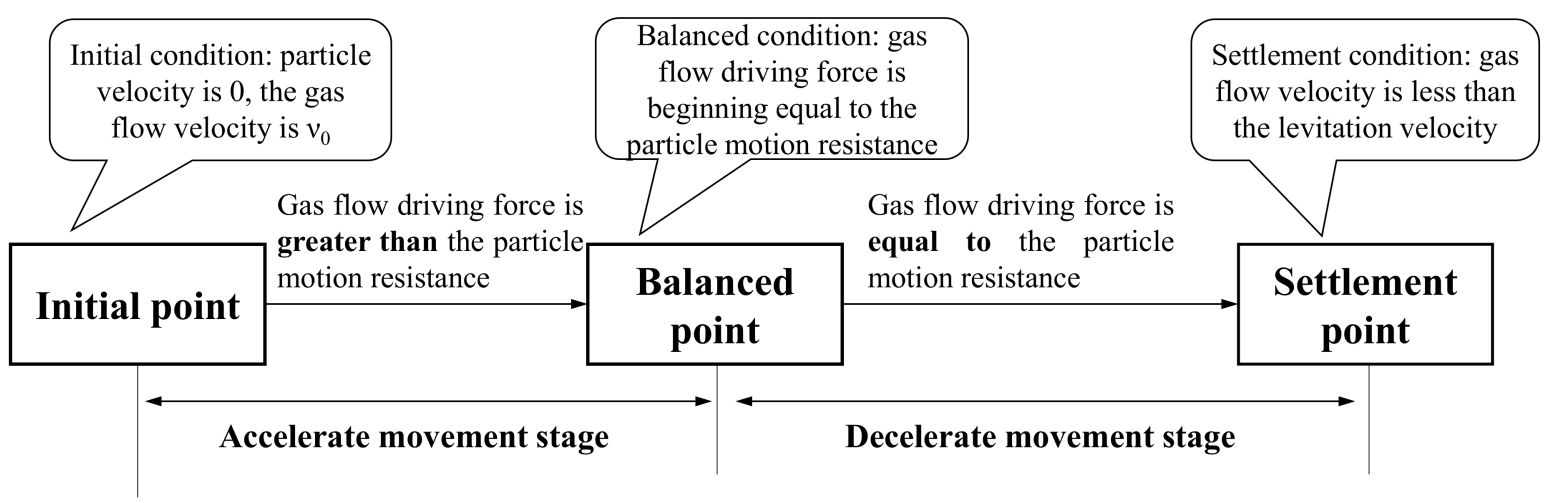

Figure 8. The pulverized coal particles migration processes.

Captured by the high-speed video camera, the images of decelerate movement and particle settling stage in the late of outburst process was recorded, as shown in Figure 9. By analyzing the location of the larger particles in the image and the corresponding time, the velocity of the coal particles could be then calculated, as shown in Table 1 . The visual frame diameter is $16 \mathrm{~cm}$, and the high-speed camera sampling frequency is $4100 \mathrm{fps}$. By observing the images taken by high-speed camera, it can be 
found that after a certain period of time, pulverized coal particle transport rate declined with time. Certain settlement could be found during the late decelerated movement stage.

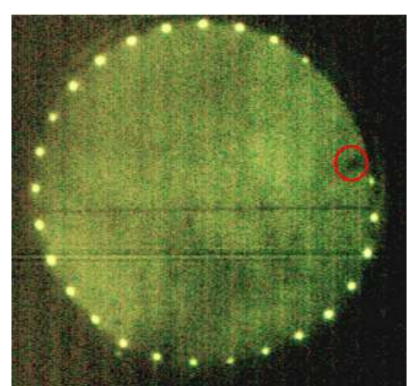

(a)

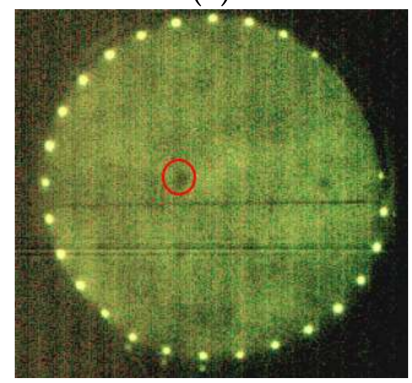

(d)

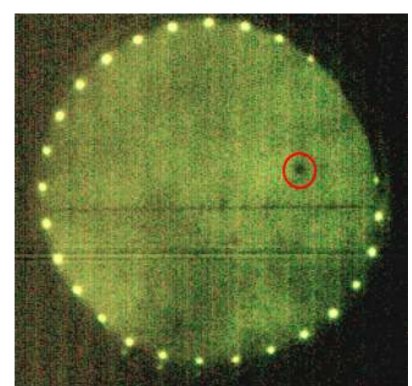

(b)

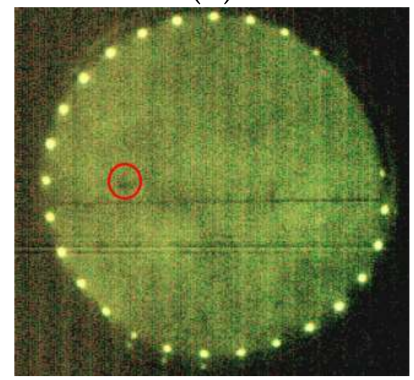

(e)

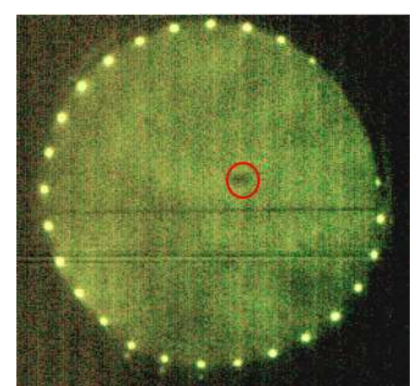

(c)

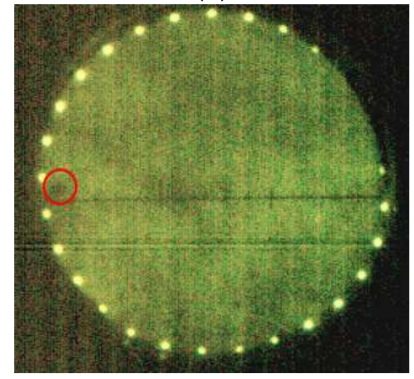

(f)

Figure 9. The images of particle migration in the late process of outburst (Observation point 4). (a) $\mathrm{t}=0$ (frame number 5339); (b) $\mathrm{t}=2.93 \mathrm{~ms}$; (c) $\mathrm{t}=5.85 \mathrm{~ms}$; (d) $\mathrm{t}=8.78 \mathrm{~ms}$; (e) $\mathrm{t}=11.71 \mathrm{~ms}$; (f) $\mathrm{t}=14.63 \mathrm{~ms}$ (frame number 5399).

Table 1. The velocity of the coal particles in late outburst process.

\begin{tabular}{cccc}
\hline Observation Point & Initial Frame Number & Final Frame Number & Velocity (m/s) \\
\hline 1 & 5006 & 5045 & 16.82 \\
2 & 5108 & 5161 & 12.38 \\
3 & 5239 & 5305 & 9.94 \\
4 & 5339 & 5399 & 10.93 \\
5 & 5577 & 5708 & 5.01 \\
\hline
\end{tabular}

\section{The Shock Wave Propagation Mechanism of the Coal and Gas Outburst}

\subsection{Expansion Energy of Gas in the Outburst Process}

In the process of coal and gas outburst, the gas expansion process can be considered as adiabatic process, meanwhile ignoring the heat exchange and energy exchange between pulverized coal, gas and roadway. When the gas pressures decay from $p_{c}$ to $p_{c 0}$, the gas volume expands from $V_{c}$ to $V_{c 0}$, the expansion work done by the gas to the air medium is

$$
w=\int_{V_{c}}^{V_{c 0}} p d V
$$

According to the adiabatic conditions

$$
p_{c} V_{c}^{n}=p_{c 0} V_{c 0}^{n}
$$

where $V_{c 0}$ is the gas quantity per ton of coal that participates in outstanding work $\left(\mathrm{m}^{3} / \mathrm{t}\right) ; n$ is the insulation index. Gas per ton of coal working on the air medium is expressed as follows 


$$
w=\frac{p_{c 0} V_{c 0}}{n-1}\left[\left(\frac{p_{c}}{p_{c 0}}\right)^{\frac{n-1}{n}}-1\right]
$$

The gas pressure involved in the outburst work performed a negative exponential function decay over time.

$$
p_{c 0}=a p_{c} e^{-b t}
$$

where $a, b$ are the fitting constant relevant to the gas desorption rate. The faster the desorption rate is, the larger the $b$ value is and the faster the pressure attenuation is; $t=x / D, D$ is the shock wave front propagation speed. When the outburst intensity is $B$, gas expansion work within a certain period is

$$
W_{t}=w B=\frac{a p_{c} e^{-b t} V_{c 0}}{n-1}\left[\left(\frac{p_{c}}{a p_{c} e^{-b t}}\right)^{\frac{n-1}{n}}-1\right] B
$$

\subsection{The Shock Wave Propagation Law of Outburst}

In order to simplify the analysis, we only considering initial and final stages of the shock wave. We researched the impact of the shock wave problem by using the ideal state of the gas expansion. Outburst shock wave formation model is shown in Figure 10. In Figure 10, $\Delta x$ is the shock thickness; outburst station is the origin of coordination. $x$ is distance of shock spreads in the roadway.

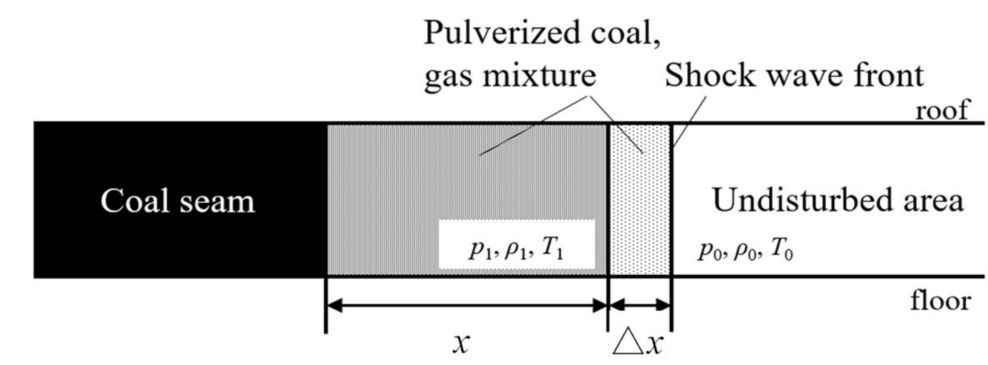

Figure 10. Shock wave formation model of coal and gas outburst.

The parameters of shock wave front are as follows.

$$
\left\{\begin{array}{l}
p_{1}=p_{0}+\frac{2}{\gamma+1} \rho_{0} D^{2}\left(1-\frac{c_{0}^{2}}{D^{2}}\right) \\
u_{1}=\frac{2}{\gamma+1} D\left(1-\frac{c_{0}^{2}}{D^{2}}\right)
\end{array}\right.
$$

where $p_{0}, \rho_{0}$ respectively, are the initial pressure and density of air in roadway; $c_{0}$ is the speed of sound; $p_{1}, \rho_{1}$ are respectively the air pressure and density of the over-shock wave front in the roadway; $\gamma$ is the gas compression factor; $u_{1}$ is the airflow speed after the shock wave front. When the cross-sectional area of the roadway is $S$, the gas mass compressed by the shock wave is concentrated in a thin layer with the thickness $\Delta x$ of the wavefront attachment, and the internal density of the thin layer is equal to the wavefront density $\rho_{1}$, then the thin layer mass $M$ is

$$
M=S \rho_{1} \Delta x=S \rho_{0} x
$$

If the velocity of gas in the thin layer with thickness $\Delta x$ is equal to the gas velocity $u_{1}$ on the wave front and the pressure is equal to $\alpha$ times the pressure on the wave front, the impulse equation in the thin-layer gas flow is

$$
\frac{d}{d t}\left(M u_{1}\right)=S\left(\alpha p_{1}-p_{0}\right)
$$


Deriving the equation,

$$
\frac{d}{d t}\left[S \rho_{0} x \frac{2 D}{\gamma+1}\left(1-\frac{c_{0}^{2}}{D^{2}}\right)\right]=S\left[\alpha p_{0}+\frac{2 \alpha \rho_{0} D^{2}}{\gamma+1}\left(1-\frac{c_{0}^{2}}{D^{2}}\right)-p_{0}\right]
$$

It can be simplified as

$$
\frac{1+\frac{c_{0}^{2}}{D^{2}}}{D(1-\alpha)\left[\left(1-\frac{c_{0}^{2}}{D^{2}}\right)+\frac{\gamma+1}{\gamma} \frac{c_{0}^{2}}{D^{2}}\right]} d D=-\frac{1}{x} d x
$$

It is assumed that the shock wave is a strong shock, therefore $c_{0}^{2} / D^{2} \approx 0$. Integrating the equation

$$
D=C x^{\alpha-1}
$$

where $C$ is the integral constant. Methane expansion work is equal to the kinetic energy of the wavefront movement and the internal energy provided by wavefront surface, then,

$$
W_{t}=\frac{1}{2} M u_{1}^{2}+\frac{1}{\gamma-1} x S p_{0}=2 S p_{0}\left(\frac{1}{(\gamma+1)^{2}}+\frac{\alpha}{\gamma^{2}-1}\right) C^{2} x^{2 \alpha-1}
$$

Based on the above equations, the shock wave propagation velocity can be present as

$$
D=C x^{\alpha-1}=\left(\frac{W_{t}}{S \rho_{0}}\right)^{\frac{1}{2}}\left[\frac{(\gamma+1)^{2}(\gamma-1)}{3 \gamma-1}\right]^{\frac{1}{2}} x^{-\frac{1}{2}}
$$

And the shock overpressure is

$$
\Delta p=p_{1}-p_{0}=\frac{2(\gamma-1)(\gamma+1)^{2} W_{t}}{(3 \gamma-1) S} x^{-1}
$$

Overpressure on the shock wave front is an important factor in the outburst. Shock wave is related intensively with strength of outburst, adsorption speed of gas, initial gas pressure, area of roadway and distance etc. The overpressure of the shock wave calculated by the model is in basically corresponding with the actual change of the overpressure measured by the experiment. Due to the response time in the position close to the outburst valve, the pressure in test is weak, as shown in Figure 11. We can summarize that the larger the initial gas pressure, the greater the strength of outburst and the overpressure of the shock wave, when the gas desorption rate remains constant.

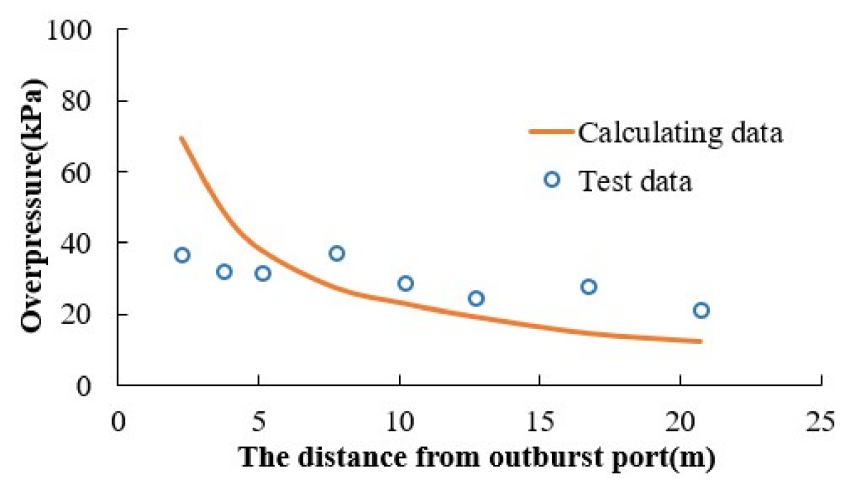

Figure 11. The relationship between shock wave overpressures and distance. 
When the size and distance of the roadway increase, the overpressure of the shock wave decreases. In the experimental conditions (The initial gas pressure is $0.35 \mathrm{MPa}$, the strength of outburst is $180.7 \mathrm{~kg}$ ), shock overpressure and fitting parameters $b$ (affected by gas desorption rate) is a quadratic function. When $b$ is taken as 3.43 , the overpressure of the shock wave reaches the maximum, and the overpressure value of the shock wave decreases as $b$ increases, as shown in Figure 12.

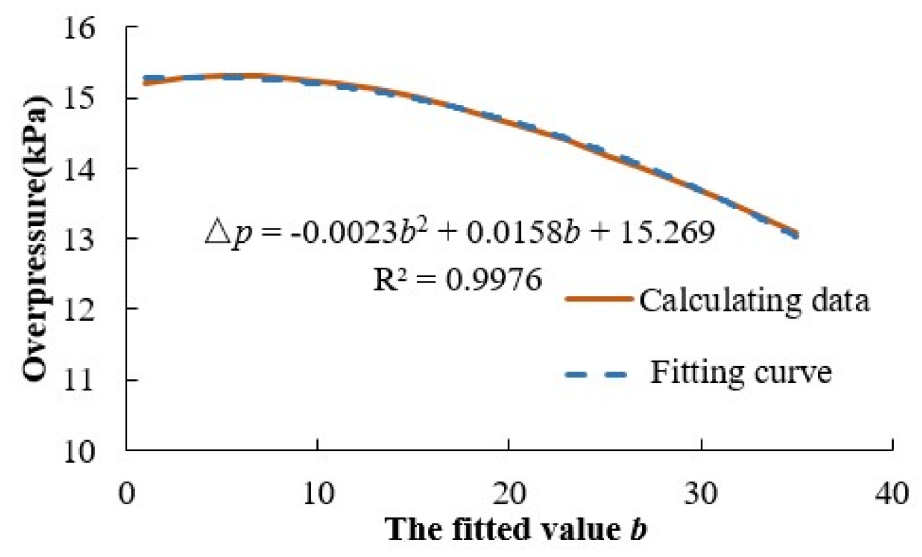

Figure 12. The relationship between shock wave overpressures and fitted value $b$ (which is relevant to the gas desorption rate).

In order to simplify the analysis, the initial and final stages of the shock wave have been considered only in above research. The derivation is made by taking the total outburst strength as a parameter. There is a certain difference between the ideal state of the actual physical test environment and the theoretical derivation. For example, during the actual outburst process, pulverized coal is gradually discharged into the roadway and migrate in the roadway, as described Section 3.4. And the distribution of pulverized coal in different roadway locations is inconsistent. Therefore, test data does not really comply with the calculated data, this will gradually improve during the study. Due to the density and desorption rate differences between $\mathrm{CO} 2$ and methane, the use of $\mathrm{CO} 2$ instead of methane in the test will lead to some differences between the test results and the actual situation. The experimental study under different gas conditions will be gradually carried out later, for discussing the effects of gas adsorption properties on the propagation of shock waves and further verifying the theoretical derivation results.

\section{Conclusions}

In conclusion, the experiment was designed to study the coal-gas two phase flow properties and its shock effect characteristics during the coal and gas outburst process. To achieve a reliable laboratory simulation test which analogies to the outburst in the field, the coal samples were selected from the outburst coal seam in Chongqing Yuyang Coal Mine, $\mathrm{China}$, and high-purity $\mathrm{CO}_{2}$ was injected as the experimental gas. A self-developed coal and gas outburst simulation test device was constructed to simulate the law of coal-gas two phase flow in the roadway of the outburst process. The mechanisms of this phenomena were explored according to the experimental results. The shock wave propagation model has been built to obtain the relationship between shock wave overpressure and its influencing factors. Based on these studies, the following understandings and conclusions can be drawn:

(1) After the outburst occurred, the air in the roadway around the outburst port was disturbed by the shock wave, and the pressure and temperature were abruptly changed. The pressure in different locations of the roadway eventually went back to the initial value after repeated fluctuations. In initial gas pressure of $0.35 \mathrm{MPa}$, the overpressure of the outburst shock wave was about $20 \sim 35 \mathrm{kPa}$, and the overpressure in the main roadway and the distance from the outburst 
port showed a decreasing trend, while the overpressure in the branch roadway increased with distance due to the reflection effect of shock wave. The change rates of temperature and gas concentration in the experiment were relatively slow than that of the gas pressure. The highest temperature in the roadway increased by $0.25^{\circ} \mathrm{C}$ and the highest concentration reached $38.12 \%$.

(2) A total weight of $180.7 \mathrm{~kg}$ pulverized coal was erupted in this experiment, most of them accumulated in the main roadway. With the action of shock air flow, the pulverized coal transportation in the roadway could be roughly divided into the accelerated movement stage, decelerated movement stage and the particle settling stage. At the late process of outburst, pulverized coal transport rate decreased with time. In the late process of decelerate movement stage, it accompanied by the settlement process.

(3) Through analyzing the law of outburst shock wave propagation, a shock wave propagation model considering the gas desorption efficiency was constructed. The relationships between shock wave overpressure and outburst intensity, gas desorption rate, initial gas pressure, cross section and distance of the roadway were obtained. Under the test conditions, the overpressure of the shock wave was quadratic with the fitting parameter $b$ (affected by gas desorption rate).

Acknowledgments: This study was financially supported by National Natural Science Foundation of China (51774319, 51574280), Chongqing Research Program of Basic Research and Frontier Technology (cstc2015jcyjBX0076), Chongqing science and technology innovation leader talent support program (CSTCKJCXLJRC14), China Postdoctoral Research Project Funding (2017M612917), and Chongqing Postdoctoral Research Project Special Funding (XM2017043).

Author Contributions: Jie Cao and Minghui Li proposed the topic of this study and designed the experiments; Linchao Dai, Bo Wang and Boning Zhai performed the experiments; Xusheng Zhao and Dongling Sun contributed analysis tools; Jie Cao and Minghui Li analyzed the data; Haitao Sun wrote the final manuscript.

Conflicts of Interest: The authors declare no conflict of interest.

\section{References}

1. Li, Z.H.; Wang, E.Y.; Ou, J.C.; Liu, Z.J. Hazard evaluation of coal and gas outbursts in a coal-mine roadway based on logistic regression model. Int. J. Rock Mech. Min. Sci. 2015, 80, 185-195. [CrossRef]

2. Liu, H.B.; Cheng, Y.P. The elimination of coal and gas outburst disasters by long distance lower protective seam mining combined with stress-relief gas extraction in the Huaibei coal mine area. J. Nat. Gas Sci. Eng. 2015, 27, 346-353. [CrossRef]

3. Yuan, L. Control of coal and gas outbursts in Huainan mines in China: A review. J. Rock Mech. Geotech. Eng. 2016, 8, 559-567. [CrossRef]

4. Ma, D.J.; Li, Z.H.; Yang, Y.L.; Tang, Y.B.; Jiang, M.M. Research on coal and gas outburst accident of Xinxing coal mine based on shock wave theory. J. Safety Sci. Technol. 2012, 8, 69-73. (In Chinese)

5. Hu, Q.T.; Wen, G.C. Mechanical Mechanism of Coal and Gas Outburst; China Science Press: Beijing, China, 2013; pp. 227-285. (In Chinese)

6. Sato, K.; Fujii, Y. Source Mechanism of a Large Scale Gas Outburst at Sunagawa Coal Mine in Japan. Pure Appl. Geophys. 1989, 129, 325-343. [CrossRef]

7. Fisne, A.; Esen, O. Coal and gas outburst hazard in Zonguldak Coal Basin of Turkey, and association with geological parameters. Nat. Hazards 2014, 74, 1363-1390. [CrossRef]

8. Zhai, C.; Xiang, X.W.; Xu, J.Z.; Wu, S.L. The characteristics and main influencing factors affecting coal and gas outbursts in Chinese Pingdingshan mining region. Nat. Hazards 2016, 82, 507-530. [CrossRef]

9. Xu, T.; Tang, C.A.; Yang, T.H.; Zhu, W.C.; Liu, J. Numerical investigation of coal and gas outbursts in underground collieries. Int. J. Rock Mech. Min. Sci. 2006, 43, 905-919. [CrossRef]

10. Xu, S.; Wang, Y.C.; Xie, J.; Wang, G. A coupled approach to simulate initiation of outbursts of coal and gas-Model development. Int. J. Coal Geol. 2011, 86, 222-230. [CrossRef]

11. Alexeev, A.D.; Revva, V.N.; Alyshev, N.A.; Zhitlyonok, D.M. True triaxial loading apparatus and its application to coal outburst prediction. Int. J. Coal Geol. 2004, 58, 245-250. [CrossRef]

12. Sobczyk, J. The influence of sorption processes on gas stresses leading to the coal and gas outburst in the laboratory conditions. Fuel 2011, 90, 1018-1023. [CrossRef] 
13. Skoczylas, N. Laboratory study of the phenomenon of methane and coal outburst. Int. J. Rock Mech. Min. Sci. 2012, 55, 102-107. [CrossRef]

14. Sobczyk, J. A comparison of the influence of adsorbed gases on gas stresses leading to coal and gas outburst. Fuel 2014, 115, 288-294. [CrossRef]

15. Peng, S.J.; Xu, J.; Yang, H.W.; Liu, D. Experimental study on the influence mechanism of gas seepage on coal and gas outburst disaster. Saf. Sci. 2012, 50, 816-821. [CrossRef]

16. Yin, G.Z.; Jiang, C.B.; Wang, J.G.; Xu, J.; Zhang, D.M.; Huang, G. A New Experimental Apparatus for Coal and Gas Outburst Simulation. Rock Mech. Rock Eng. 2016, 49, 2005-2013. [CrossRef]

17. Geng, J.B.; Xu, J.; Nie, W.; Peng, S.J.; Zhang, C.L.; Luo, X.H. Regression analysis of major parameters affecting the intensity of coal and gas outbursts in laboratory. Int. J. Min. Sci. Technol. 2017, 27, 327-332. [CrossRef]

18. Tu, Q.Y.; Cheng, Y.P.; Guo, P.K.; Jiang, J.Y.; Wang, L.; Zhang, R. Experimental Study of Coal and Gas Outbursts Related to Gas-Enriched Areas. Rock Mech. Rock Eng. 2016, 49, 3769-3781. [CrossRef]

19. Zhao, W.; Cheng, Y.P.; Jiang, H.N.; Jin, K.; Wang, H.F.; Wang, L. Role of the rapid gas desorption of coal powders in the development stage of outbursts. J. Nat. Gas Sci. Eng. 2016, 28, 491-501. [CrossRef]

20. $\mathrm{Xu}, \mathrm{L} . \mathrm{H} . ;$ Jiang, C.L. Initial desorption characterization of methane and carbon dioxide in coal and its influence on coal and gas outburst risk. Fuel 2017, 203, 700-706. [CrossRef]

21. Otuonye, F.; Sheng, J. A numerical simulation of gas flow during coal/gas outbursts. Geotech. Geol. Eng. 1994, 12, 15-34. [CrossRef]

22. Fedorov, A.V.; Fedorchenko, I.A. Numerical modeling of the coal-and-gas outburst gasdynamics. J. Min. Sci. 2010, 46, 473-484. [CrossRef]

23. Fedorchenko, I.A.; Fedorov, A.V. Gas-Dynamic Stage of the Coal and Gas Outburst with Allowance for Desorption. J. Min. Sci. 2012, 48, 15-26. [CrossRef]

24. Sun, D.L.; Hu, Q.T.; Miao, F.T. Motion state of coal-gas flow in the process of outburst. J. China Coal Soc. 2012, 37, 452-458. (In Chinese)

25. Miao, F.T.; Sun, D.L.; Hu, Q.T. The formation mechanism of shock waves in the coal and gas outburst process. J. China Coal Soc. 2013, 38, 367-372. (In Chinese)

26. Zhao, W.; Cheng, Y.P.; Guo, P.K.; Jin, K.; Tu, Q.Y.; Wang, H.F. An analysis of the gas-solid plug flow formation new insights into the coal failure process during coal and gas outbursts Original. Powder Technol. 2017, 305, 39-47. [CrossRef]

27. Wang, K.; Zhou, A.T.; Zhang, J.F.; Zhang, P. Real-time numerical simulations and experimental research for the propagation characteristics of shock waves and gas flow during coal and gas outburst. Saf. Sci. 2012, 50, 835-841. [CrossRef]

28. Zhou, A.T.; Wang, K.; Wang, L.; Du, F.; Li, Z.L. Numerical simulation for propagation characteristics of shock wave and gas flow induced by outburst intensity. Int. J. Min. Sci. Technol. 2015, 25, 107-112. [CrossRef]

29. Cao, J.; Sun, H.T.; Dai, L.C.; Sun, D.L.; Wang, B.; Miao, F.T. Simulation research on dynamic effect of coal and gas outburst. J. China Univ. Min. Technol. 2018, 47, 100-107. (In Chinese)

30. Wang, X.S.; Xie, Z.K. A discussion on the safety distance in case of gas explosion. J. China Univ. Min. Technol. 1989, 18, 1-8. (In Chinese) [CrossRef]

(C) 2018 by the authors. Licensee MDPI, Basel, Switzerland. This article is an open access article distributed under the terms and conditions of the Creative Commons Attribution (CC BY) license (http://creativecommons.org/licenses/by/4.0/). 